\title{
THERMAL PROPERTIES AND STRUCTURE OF CAST CARBON-CONTAINING INVAR AND SUPERINVAR ALLOYS AFTER TWO-STAGE ANNEALING
}

\author{
S. V. Grachev, ${ }^{1}$ M. A. Filippov, ${ }^{1}$ V. I. Chermenskii, ${ }^{1}$ M. D. Kharchuk, ${ }^{1}{ }^{\text {I. }}$ V. Konchakovskii, ${ }^{1}$ \\ A. S. Zhilin, ${ }^{1}$ V. V. Tokarev, ${ }^{1}$ and S. M. Nikiforova ${ }^{1}$
}

Translated from Metallovedenie i Termicheskaya Obrabotka Metallov, No. 3, pp. 10 - 13, March, 2013.

The effect of carbon content on thermal properties of cast superinvar alloys subjected to two-stage annealing is studied. It is shown that carbon improves the casting properties of the alloys but raises the temperature coefficient of linear expansion (CTLE). Two-stage high-temperature annealing makes it possible to remove carbon from the solid solution and to transfer it into graphite, which is accompanied by decrease in the CTLE.

Key words: superinvar, solid solution, homogenization, graphite, lattice parameter, dendritic segregation, residual stresses.

\section{INTRODUCTION}

Invar and superinvar alloys belong to a group with special thermal properties [1]. One of the main characteristics of such alloys is the temperature coefficient of linear expansion (CTLE). The alloys have a low and constant CTLE in a specific temperature range known as the invar interval. They are applied primarily in instrument making for fabricating equipment components that should have permanent sizes. By the data available [2] the alloys in question are also used in the oil and gas industry.

A typical structure responsible for invar properties of alloys is an iron-nickel ferromagnetic solid solution with an fcc lattice. The invar interval is determined by point $M_{\mathrm{s}}$ on the side of low nickel concentrations and by the Curie point on the side of elevated nickel concentrations. A classical invar alloy contains $36 \% \mathrm{Ni}$ and iron as the remainder. It has been suggested in the middle 1930s (primarily by Japanese researchers [1]) that a part of nickel atoms in an invar should be replaced by cobalt atoms. Such alloys are known as superinvars. The relevant literature contains much information on the thermal properties of deformable invar alloys [1]. Today it has become necessary to produce complex-shape parts from invar and superinvar alloys, which are hard and sometimes even impossible to form by pressure treatment.

1 Ural Federal University (UrFU) in the Name of the First President of Russia B. N. Eltsyn, Ekaterinburg, Russia (e-mail: zh-al@yandex.ru).
These are articles for the rocket and space industry, optoelectronics, tracker stations, etc. It is known [3] that alloys with a structure of solid solution have low casting properties and acquire flaws like pores and discontinuities during casting.

Processes for casting invar parts with carbon additives are developed today in different countries (Japan, USA, Russia). The action of carbon on the properties of invar and superinvar alloys is ambiguous. A low content of carbon promotes growth in the strength properties of invar and superinvar alloys and widens the invar interval [1]. In the presence $0.5 \mathrm{wt} . \%$ and higher concentrations of carbon the casting properties of invars are improved substantially making it possible to obtain quality castings. However, considerable carbon concentrations in invars raise the CTLE, which is not desirable. For this reason, cast articles from carbon invar and superinvar alloys should be annealed for removing carbon from the solid solution and forming graphite. Graphite also raises the CTLE of invar and superinvar alloys. However, the volume fraction of graphite is relatively low and its effect is much lower than that of carbon present in the solid solution. Thus, we may speak of "temporary alloying" of invar and superinvar alloys with carbon. Castings from carbon invar alloys are commonly subjected to two-stage annealing at $960^{\circ} \mathrm{C}$ for $4 \mathrm{~h}$ and at $680^{\circ} \mathrm{C}$ for $2 \mathrm{~h}$. This mode of heat treatment of castable carbon invars promotes segregation of an enough volume of carbon from the solid solution and lowering of the CTLE. It should be noted that dendritic segregation is another factor affecting the CTLE of castable invar al- 
TABLE 1. Chemical Compositions of Carbon-Containing Superinvar Alloys

\begin{tabular}{lcccc}
\hline \multicolumn{1}{c}{ Alloy } & & $\mathrm{Ni}$ & \multicolumn{1}{c}{$\mathrm{Co}$} & \multicolumn{1}{c}{$\mathrm{C}$} \\
\hline $\mathrm{Fe}-31.0 \% \mathrm{Ni}-10 \% \mathrm{Co}$ & $(1)$ & 31.0 & 9.96 & - \\
$\mathrm{Fe}-30.4 \% \mathrm{Ni}-9.8 \% \mathrm{Co}-0.35 \% \mathrm{C}$ & $(2)$ & 30.4 & 9.8 & 0.35 \\
$\mathrm{Fe}-30.3 \% \mathrm{Ni}-9.2 \% \mathrm{Co}-0.71 \% \mathrm{C}$ & $(3)$ & 30.3 & 9.2 & 0.71 \\
$\mathrm{Fe}-29.7 \% \mathrm{Ni}-10.0 \% \mathrm{Co}-1.08 \% \mathrm{C}(4)$ & 29.7 & 10.0 & 1.08 \\
$\mathrm{Fe}-29.4 \% \mathrm{Ni}-10.0 \% \mathrm{Co}-1.67 \% \mathrm{C}(5)$ & 29.4 & 10.0 & 1.67 \\
\hline
\end{tabular}

loys. Any deviation of the concentration of nickel toward values higher or lower than $36 \%$ causes increase in the CTLE of castable invars. Moreover, the presence of domains with a lower content of nickel may stimulate a martensitic transformation and a loss of the invar properties of the alloy.

The mode of two-stage annealing applied to castable invar and superinvar alloys differs from the classical heat treatment (quenching or quenching followed by low-temperature tempering) of deformable invars. In particular, the second annealing promotes considerable relaxation of residual stresses, both peak ones and background ones, which is a necessary condition for stable operation of articles in the whole of the invar range.

At the same time, there is an opinion that every group of invar and superinvar alloys should be heat treated in an individual mode [1], which is especially important for castable invars because the crystallization process depends considerably on the mass of the article, on the development of dendritic segregation, on the rate of crystallization and on other factors.

The aim of the present work was to study the functional properties of castable invar and superinvar alloys with different contents of carbon after two-stage annealing.

\section{METHODS OF STUDY}

The alloys studied were melted from pure blend materials, i.e., nickel of grade $\mathrm{N} 1$ and cobalt of grades $\mathrm{K} 0$ and $\mathrm{K} 1$. Under laboratory conditions we melted carbon invar and superinvar alloys with different carbon contents and, for comparison, a carbon-free alloy $\mathrm{Fe}-31.0 \% \mathrm{Ni}-10 \% \mathrm{Co}$ (see Table 1).

We studied the structure of the invar alloys after casting and two-stage annealing at $960^{\circ} \mathrm{C}$ for $4 \mathrm{~h}$ and at $680^{\circ} \mathrm{C}$ for $2 \mathrm{~h}$. In an unetched condition graphite segregations with various shapes and sizes distributed over the volume were observed under a magnification of $\times 200$. To determine the volume fraction of free graphite we used the method of Glagolev [4]. The structure of the dendrites was studied with the help of an Altami MET 1M microscope under a magnification of $\times 200$. We used a Jeol JSM 5900LV (Japan) scanning electron microscope equipped with an Inca Energy 200 (Oxford, Great Britain) energy dispersive spectrometer for microscopic x-ray spectrum analysis and for determining the
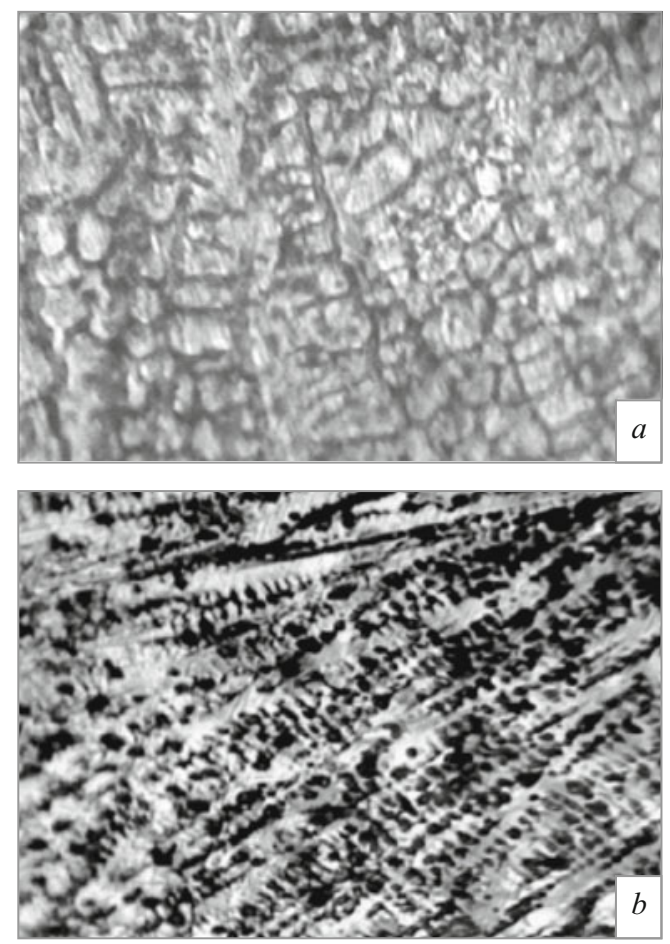

Fig. 1. Structures of a carbonless superinvar (alloy 1$)(a)$ and of a carbon superinvar (alloy 5 ) $(b)$ after etching. $\times 200$.

content of elements over cross section. We estimated the maximum and minimum concentrations of the elements. The variation of the lattice parameter during annealing of the cast invar alloys was determined in cobalt $K_{\alpha}$ radiation using a DRON-2 diffractometer. The microhardness of the alloys was measured with the help of a PMT-3 device under a load of $0.5 \mathrm{~N}$. To determine the CTLE we used specially designed low-temperature and high-temperature dilatometers. We established that the matrix of the alloys had a superinvar composition with $30 \% \mathrm{Ni}+10 \% \mathrm{Co}$. If necessary, we determined the mean values of the CTLE in specific temperature ranges, i.e., $\alpha_{20-200}$ and $\alpha_{20-400}$.

\section{RESULTS AND DISCUSSION}

A typical structure of carbon and carbonless castable superinvar alloys is a dendrite-cellular one. As an example, we present such a structure in Fig. 1.

Cast superinvar alloys possess a dendritic structure, where carbon refines considerably the structure of the dendrites. Graphite segregations are observed primarily in dendrite spacings, where the carbon content can be elevated due to the development dendritic segregation with respect to carbon. We studied the morphology, the size, and the arrangement of graphite on unetched laps. Graphite inclusions of different sizes and shapes can be seen in Fig. 2, where the larger inclusions represent the primary graphite segregated directly due to crystallization, wheres the smaller inclusions 

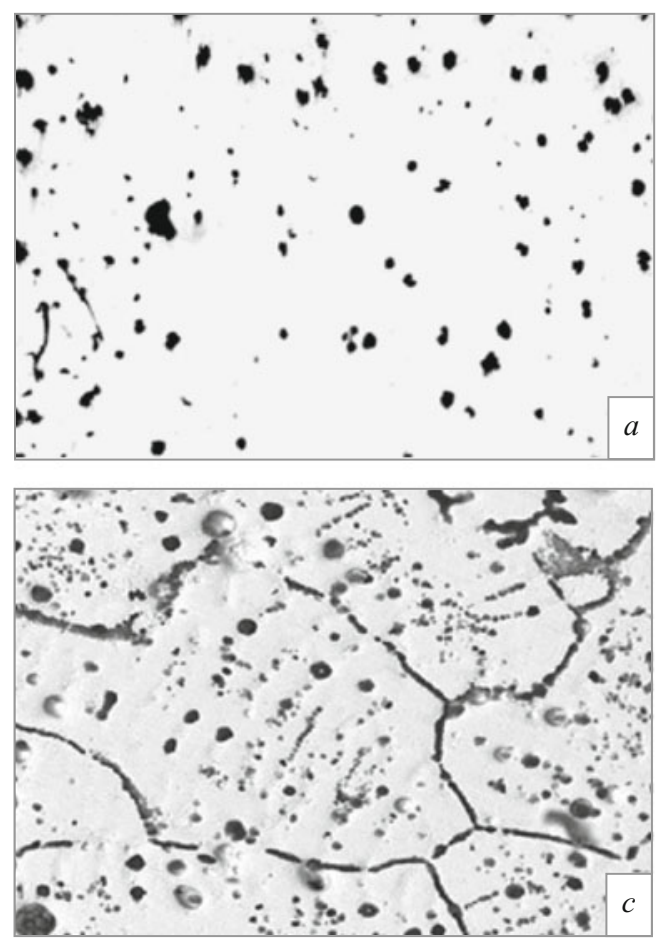

seem to have formed due to annealing. The graphite inclusions formed in the annealing process can be located over the whole of the volume of the lap (Fig. $2 a$ and $b$ ). In some cases

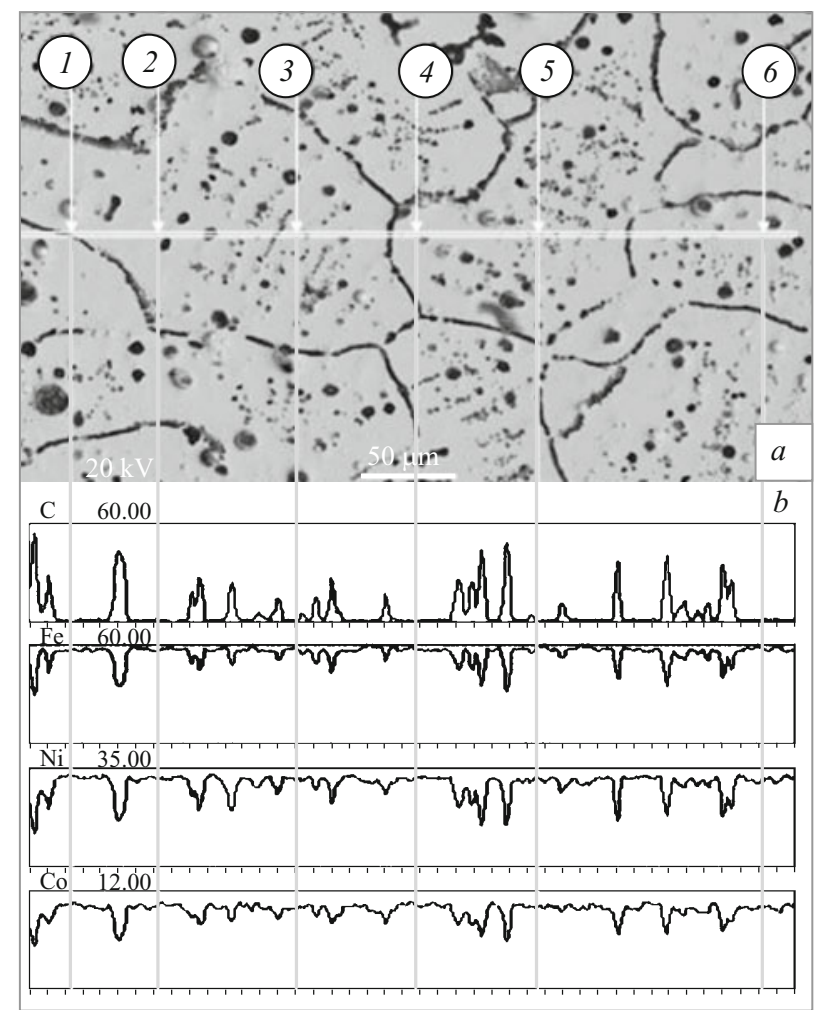

Fig. 3. Structure $(a)$ and distribution of elements over cross section $(b)$ in alloy 5 .

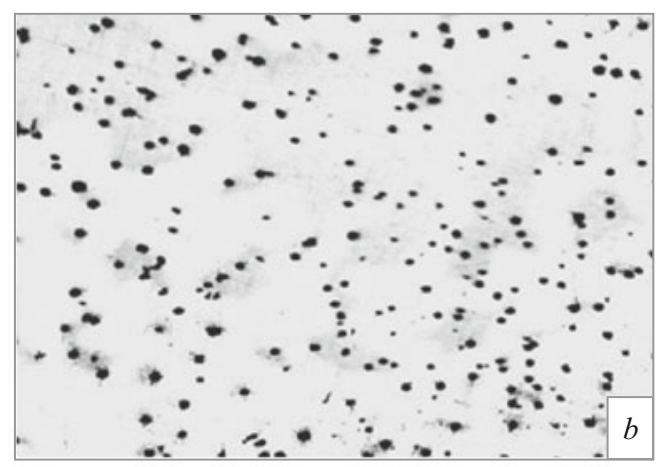

Fig. 2. Structures of carbon superinvars $(\times 200)$ : $a, b)$ alloy 2 in cast condition; $c$ ) alloy 5 after two-stage annealing at $960^{\circ} \mathrm{C}$ for $4 \mathrm{~h}$ and at $680^{\circ} \mathrm{C}$ for $2 \mathrm{~h}$.

they have the form of rings (Fig. 1c) lying presumably over boundaries of coarse grains of the solid solution formed after partial weakening of the dendritic segregation.

It should be noted that graphite can also be segregated in dendrite spacings. Graphite inclusions may have a globular or a vermicular shape, and the volume fraction of free graphite increases upon growth in the carbon content in the alloy. A high content of carbon in the alloy causes graphite segregation in the form of a net over grain boundaries of the solid solution.

The lattice parameter of the solid solution increases regularly upon growth in the carbon content in the alloy, which indicates preservation of some dissolved carbon, the proportion of which can be lowered in the alloy by subsequent annealing.

To provide a fuller segregation of carbon from the solid solution of the alloys we subjected the latter to a high-temperature annealing at $1000^{\circ} \mathrm{C}$ for $6 \mathrm{~h}$ and cooling with the furnace. Such annealing did not remove the dendritic structure, but the boundaries of the dendrites became smeared and the content of free graphite increased. A study of the graphite segregations showed that they were larger after the crystallization than after the annealing.

To consider the variation of the concentrations of the base nickel and cobalt components over the volume we resorted to a microscopic x-ray spectrum analysis. We studied the alloys in cast and annealed conditions. The distribution of nickel and cobalt over the cross section of the ingots was quite uniform without peak concentrations, but we detected some growth in their contents on the boundaries of dendrite cells (Fig. 3). 
$C_{\mathrm{gr}}, \mathrm{vol} \%$
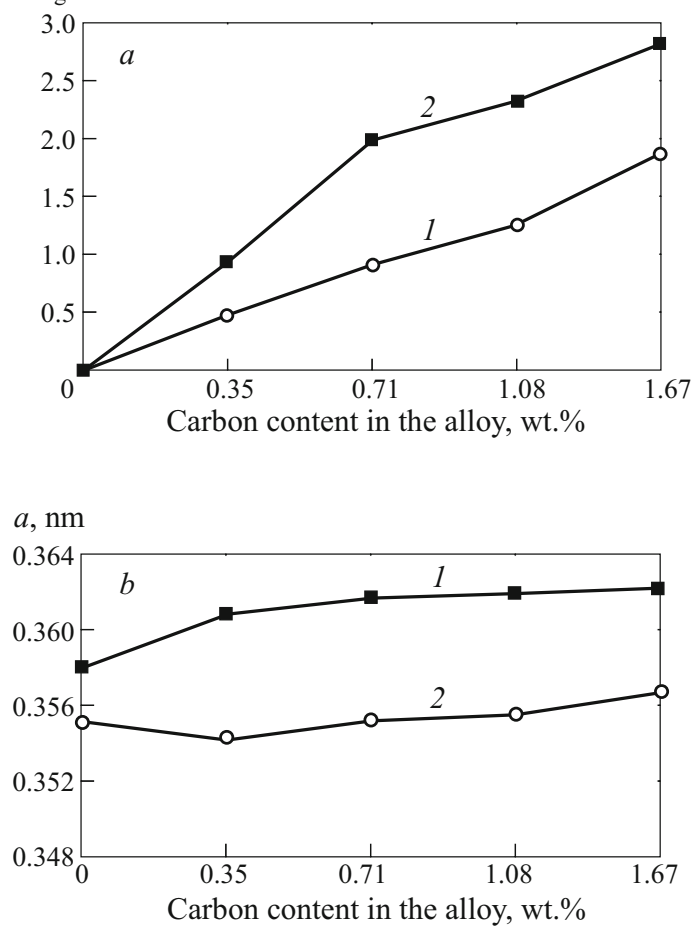

Fig. 4. Dependence of the volume fraction of graphite $(a)$ and of the lattice parameter of austenite $(b)$ on the content of carbon in invar alloys: 1 ) in cast condition; 2 ) after two-stage annealing at $960^{\circ} \mathrm{C}$ for $4 \mathrm{~h}$ and at $680^{\circ} \mathrm{C}$ for $2 \mathrm{~h}$.

Annealing levels the concentrations of nickel and cobalt; their maximum content in the volume of a dendrite cell decreases by about a factor of 2 . Note that the development of dendritic segregation in cast invar alloys is low, which is explainable, in particular, by the small range of crystallization and the high diffusivity of nickel and cobalt, which are not carbide forming elements, in the iron-nickel solid solution. It is known that growth of the crystallization range intensifies dendritic segregation in the alloy. On the other hand, the relatively low development of dendritic segregation prolongs the time to its complete removal. Computations show that complete removal of dendritic segregation and leveling of the chemical composition over the volume takes several tens of hours at a temperature of $1200^{\circ} \mathrm{C}$. However, it should be stressed that the segregation of graphite in castable carbon superinvars occurs quite intensely, which makes it possible to obtain the required mean values of the CTLE and to use these annealing modes for specific commercial articles.

It should be noted that the data obtained allow us to determine the temperature ranges corresponding to intense enough segregation of carbon. Figure $4 a$ presents the volume fraction of graphite in alloys with different carbon contents.

These results are not strict and do not reflect complete segregation of excess carbon from the solid solution. Figure $4 b$ shows the variation of the lattice parameter of $\gamma$-sold solution as a function of carbon content in the alloy. It can be
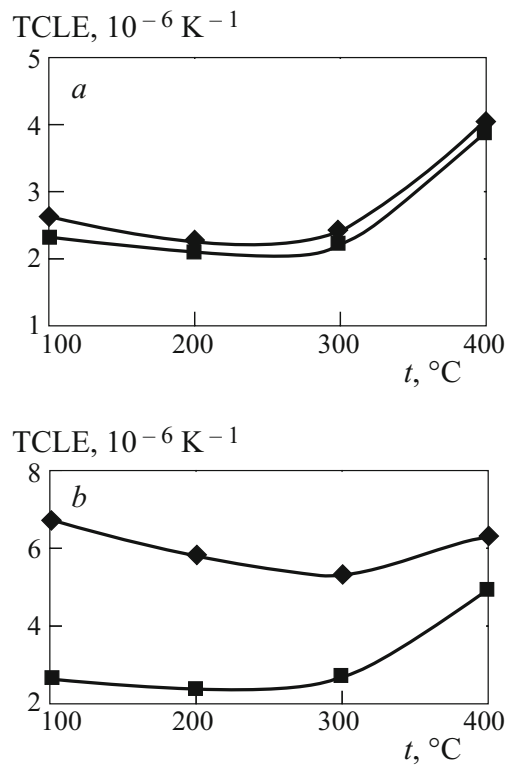

TCLE, $10^{-6} \mathrm{~K}^{-1}$
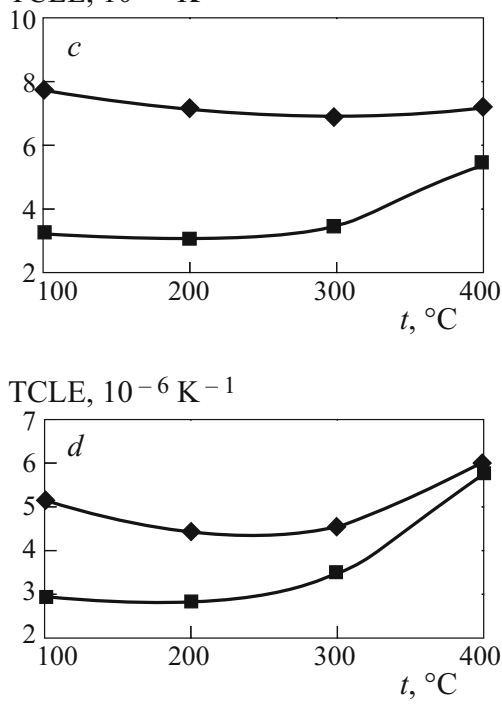

Fig. 5. Dependence of the mean temperature coefficient of linear expansion (CTLE) of superinvar alloys $1(a), 3(b), 4(c)$, and $5(d)$ on the heating temperature: $\bullet$ ) in cast condition; $\boldsymbol{\square})$ after two-stage annealing at $960^{\circ} \mathrm{C}$ for $4 \mathrm{~h}$ and at $680^{\circ} \mathrm{C}$ for $2 \mathrm{~h}$.

seen that the lattice parameter increases upon growth in the carbon content.

The microhardness of the annealed carbon superinvar alloys matches approximately the microhardness of iron-nickel alloys studied in other works.

Figure 5 presents the results of measurements of the CTLE of carbon superinvar alloys in cast and annealed states.

It can be seen that the CTLE of all the cast superinvar alloys increases upon heating. The lowest value of the CTLE has been obtained for the classical carbonless superinvar (alloy 1 ), i.e., $\alpha_{20-400}=3.92 \times 10^{-6} \mathrm{~K}^{-1}$. At the same time, the carbon castable superinvar alloys exhibit quite low values of 
CTLE $\left(3.5 \times 10^{-6} \mathrm{~K}^{-1}<\alpha<6.5 \times 10^{-6} \mathrm{~K}^{-1}\right)$ close to the value of the CTLE of such materials as ceramics and soft glass. All the alloys in the temperature range below $300^{\circ} \mathrm{C}$ have $\alpha<3.5 \times 10^{-6} \mathrm{~K}^{-1}$ except for alloy 2 . An anomaly of the invar alloys is decrease in the CTLE upon heating to $300^{\circ} \mathrm{C}$ and increase in the CTLE upon further heating to $400^{\circ} \mathrm{C}$ and higher temperatures. It can be seen from the data of Fig. 5 that heating produces a considerable effect on the CTLE. The difference between the values of the CTLE in cast and annealed conditions decreases upon growth in the heating temperature. At the same time, heating does not virtually change the CTLE of the classical carbonless invar alloy. This means that the main reason behind the growth in the CTLE of cast carbon superinvar alloys in cast condition is the presence of carbon in the iron-nickel solid solution rather than the dendritic segregation.

\section{CONCLUSIONS}

1. Introduction of carbon into castable invar and superinvar alloys improves their casting properties. Simultaneously, carbon raises the values of the temperature coefficient of linear expansion (CTLE).

2. Carbon in invar and superinvar alloys can be present in the solid solution, in carbides or in the form of graphite. The carbon in the solid solution raises the CTLE the most significantly. When the carbon content in a cast alloy is increased, the lattice parameter of the $\gamma$-solid solution grows and so does the volume fraction of free carbon in the form of graphite.

3. In the process of two-stage high-temperature annealing carbon in invar and superinvar alloys segregates from the solid solution additionally in the form of graphite. The value of the CTLE decreases considerably.

4. The volume fraction of free graphite after two-stage high-temperature annealing is the higher the more carbon the alloy contains. When carbon is segregated from the ironnickel solid solution, the lattice parameter of the $\gamma$-solid solution decreases.

The study has been performed with financial support of young scientists of the UrFU within implementation of the Program of Development of the UrFU.

\section{REFERENCES}

1. A. I. Zakharov, The Physics of Precision Alloys with Special Thermal Properties [in Russian], Metallurgiya, Moscow (1986), $238 \mathrm{p}$.

2. G. V. Shcherbedinskii and Yu. L. Rodionov, "Multifunctional alloys with controlled set of hard-to-combine mechanical and physicochemical properties," Metally, No. 5, 132 - 135 (2000).

3. I. I. Novikov, G. B. Stroganov, and A. I. Novikov, Metal Science, Heat Treatment and X-Ray Imaging [in Russian], MISiS, Moscow (1994), $479 \mathrm{p}$.

4. S. A. Saltykov, Stereometric Metallography, Metallurgiya, Moscow (1978), $271 \mathrm{p}$. 